\title{
The nature of accessibility studies
}

Gian Maria Greco ${ }^{\bowtie}$

TransMedia Catalonia, Universitat Autònoma de Barcelona

Galician Observatory for Media Accessibility, Universidade de Vigo
Citation: Greco, G.M. (2018). The nature of accessibility studies. Journal of Audiovisual Translation, 1(1), 205-232.

Editor(s): A. Jankowska \& P. RomeroFresco

Received: January 22, 2018

Accepted: June 30, 2018

Published: November 15, 2018

Funding: This project has received funding from the European Union's Horizon 2020 research and innovation programme under the Marie Sklodowska-Curie grant agreement No 752659 (project UMAQ).

Copyright: @2018 Greco. This is an open access article distributed under the terms of the Creative Commons Attribution License. This allows for unrestricted use, distribution, and reproduction in any medium, provided the original author and source are credited.

\section{Abstract}

Accessibility has come to play a pivotal role on the world's stage, gradually pervading different aspects of our lives as well as a vast range of fields, giving rise to a plethora of fruitful new ideas, methods and models, and becoming an ever more key issue within a process that is reshaping the very fabric of society. The ubiquitous effects of accessibility have led to the emergence of a new research field, namely accessibility studies (AS). This paper presents both the path that has led towards the emergence of AS as well as the distinctive features of this new field. AS is defined as the field concerned with the investigation of accessibility processes and phenomena, and the design, implementation and evaluation of accessibility-based and accessibilityoriented methodologies. The analysis is carried out mainly, though not exclusively, in reference to media accessibility (MA), as it is one of the most mature areas in which the process of the formation of AS has been taking place. It concludes by arguing that AS is a timely field that addresses the most pressing issues our society is facing nowadays and appealing to MA to embrace its identity as an area of AS.

Key words: access, accessibility, accessibility revolution, accessibility studies, accessible filmmaking, affordances, audiovisual translation, design, human-computer interaction, human rights, information revolution, interdisciplinarity, Isotype, media accessibility, maker-user gap, Marie Neurath, Otto Neurath, universal access, universal access in humancomputer interaction

${ }^{凶}$ gianmaria.greco@gmail.com; https://orcid.org/0000-0002-8714-6349 
Marco Polo describes a bridge, stone by stone.

"But which is the stone that supports the bridge?" Kublai Khan asks.

"The bridge is not supported by one stone or another," Marco answers, "but by the line of the arch that they form."

Kublai Khan remains silent, reflecting.

Then he adds: "Why do you speak to me of the stones?

It is only the arch that matters to me."

Polo answers: "Without stones there is no arch."

(Calvino, 1974, p. 82)

\section{Introduction}

Accessibility has come to play a pivotal role on the world's stage. Over the course of a movement born almost a century ago, accessibility has been gradually pervading different aspects of our lives as well as a vast range of fields, giving rise to a plethora of fruitful new ideas, methods and models, and becoming an ever more key issue within a process that is reshaping the very fabric of society. The ubiquitous effects of accessibility have, of late, led some scholars to argue for the emergence of a new research field, namely accessibility studies (AS) (e.g. Greco, 2016b, 2017; Jankowska, forthcoming; Romero-Fresco, 2017b, forthcoming). Yet, a presentation of both the path behind the emergence of AS and its distinctive features is still missing. In this paper, the first steps towards bridging this gap will be taken; the footpath of the analysis of a new field tread by many others before will be embarked upon. Since one is as good as the company she keeps, in the following pages there will be a careful attempt to retrace the steps of those successful explorers, while being vigilant to the turns and obstacles presently laid out by accessibility. However, in doing so, I will dissatisfy Calvino's Kublai Khan and Marco Polo, for I will neither describe each single stone that makes the bridge of AS nor detail the line of arch that supports it. The line of arch as well as each single stone deserve a space longer than the one I have at my disposal. Therefore, my goal is to sketch a general overview of the field of AS, which makes the character of this paper propaedeutic; that is, I aim to present an initial analysis of the distinctiveness of AS and prepare it for future systematic studies.

More specifically, in the following pages I will start out by introducing the theoretical and social revolution sparked by accessibility through its connections with two other revolutions: that produced by human rights and that by information and communication technologies (ICTs). I will then present three shifts common to the fields where accessibility has come to play a key role, namely, the shift from particularist accounts to a universalist account of accessibility, the shift from a maker-centred to a user-centred approach, and the shift from reactive to proactive approaches. Next, I will analyse the role that internal and external forces - interdisciplinarity, the formation of a new research community, and the opposition from well-established fields - 
have been playing in the formation of AS. I will go on to introduce and briefly discuss a definition of AS and trace its origins to the work of Otto and Marie Neurath, to then conclude by outlining what lies ahead of AS. Though the emergence of AS involves a vast number of research areas, whenever possible, examples from the areas of audiovisual translation (AVT) and media accessibility (MA) will be used, given the scope of this journal and also, so as not to make the paper anecdotal.

\section{The roots of the accessibility revolution}

The first cry of accessibility in contemporary thought and society can be traced back to the same intense debate as that on human dignity, equality, autonomy, and participation that took place in the first decades of the last century, between the end of WWI and that of WWII. During this time, the idea that human beings needed some material and immaterial goods to live a decent life became the centre of a widespread movement that, among its many effects, led to the adoption of the Universal Declaration of Human Rights (UDHR). Human rights rest upon two intertwined grounds: human dignity and access. The importance of the former is evident in the fact that it is the very first concept introduced in the preamble of the UDHR. This concept of human dignity sets a minimum standard of quality of life an individual is entitled to for the sole reason of being a human being. In turn, such a standard is defined by a series of material and immaterial goods (i.e. the objects of human rights) thought to be essential for every human being in order to fulfil her humanity. Without food, work, education, or cultural life, an individual is deprived of her dignity qua human being. Yet, guaranteeing the mere existence of those goods does not suffice in assuring a dignified life. The fact that a state doesn't deplete and pollute water resources is not sufficient grounds for it to claim that it is respecting the right to water. In order to claim so, it must also provide the necessary means for everyone to access those water resources (Singh, 2016). Setting up a public education system does not suffice for a state to claim that it is respecting the right to education, if said system does not also provide the means to access for every student. Guaranteeing the conditions for the existence of fundamental material and immaterial goods is a necessary but not sufficient condition for human dignity; the possibility to have actual access to them also needs to be in place (Francioni, 2007). In turn, the requirement of access entails that "everyone has an adequate quantity and quality of that object [of a human right], given their particular natural and social circumstances" (Buitenweg, 2007, p. 269; see also Scanlon, Cassar, \& Nemes, 2004). Controlling access to such goods has been one of the main and most effective instruments used by power structures: social control through the decision over who gets access to what, how, and when (Foucault, 2007; Morris, 2012). In the UDHR only two rights are explicitly formulated in terms of access. Since then, the use of the formula "the right to access to $x$ " instead of "the right to $x$ " has been steadily increasing in international texts and human rights treaties. The key role played by accessibility has been made further explicit by the United Nations in a series of documents published over the years, most famously, the General Comment on the Right to Adequate Food (art. 11 of the UDHR) adopted in 1999 by the UN Committee on Economic, Social and Cultural Rights. A General Comment provides an authoritative interpretation of an article related to a human rights treaty as well as some precise 
measures to be taken in order to comply with the obligations under that specific article; that is, it provides concrete meaning to the right expressed in the article. The General Comment on the Right to Adequate Food makes explicit that human rights impose four distinct kinds of obligations, three of which are based on accessibility, namely: "duties to respect human rights, duties to protect (secure access to the objects of) human rights, duties to provide (secure access to) the objects of human rights, and duties to facilitate human rights fulfilment" (Pogge, 2011, p. 8)', as well as an obligation to facilitate, which means that "the State must pro-actively engage in activities intended to strengthen people's access to and utilization of" the objects of human rights (UN Committee on Economic, Social and Cultural Rights, 1999, p. 5)". Consequently, access does not merely mean for an individual to have a good at her disposal or to have the possibility to reach it. Having access also means being able to use, interact with, and enjoy that good. Thanks to the cultural revolution produced by human rights, it has become clear that access is a necessary requirement for the respect of the human dignity of all. From this point of view, accessibility then becomes a proactive principle for human rights, which calls for an equally proactive attitude from the dutybearers to comply with that necessary requirement (Greco, 2016b). As we will see later, this has made accessibility a key instrument in many international policies, not only those concerning exclusively human rights.

In order for the accessibility revolution to fully blossom into what it is today, a second condition was needed; this time related to the nature of our world and the ways we access it. In short, it needed the information revolution. Over the past few decades, ICTs have been changing the very nature of the world we live in. They are not "mere tools but rather social forces that are increasingly affecting our self-conception (who we are), our mutual interactions (how we socialise); our conception of reality (our metaphysics); and our interactions with reality (our agency)" (Floridi, 2015, p. 2). They are modifying the very mechanisms through which we access the world, ourselves, and others. A 2004 preparatory document for the UNESCO World Summit on the Information Society, entitled Social Transformation in an Information Society: Rethinking Access to You and the World, highlights how access is at the centre of one of the most disruptive effects of the information society. More precisely, it discusses the "reconfiguration of access enabled by these new digital choices", which is challenging "fundamental social and political notions of freedom, control, personal responsibility, and shared community values" (Dutton, 2004, p. 70). The document shows how, by reconfiguring access, ICTs are creating "more than just new connections. [They enable] the opening and closing of new forms of personal, social, and economic capacities, relationships, and power-plays" (Dutton, 2004, p. 19). They are creating new social inequalities through the formation of multiple divides, beyond the traditional framing of a digital divide between those who have physical access to ICTs and those who have not. A similar warning was recently made by the Internet Society in a report that summarises the results of a worldwide survey "to better understand the forces of change" (Internet Society, 2017, p. 7) in the coming years. According to the report: "existing inequities between the "haves" and the "have nots" could be exacerbated as technology changes move faster and faster" (Internet Society, 2017, p. 79). In the information age, accessibility becomes the ground on which power negotiations and social struggles take place. Consider the issue 
of languages on the web, which "serves as a counter to the perceived concentration of issues surrounding the information society on ICTs and their impact" (UNESCO Institute for Statistics, 2005, p. 7), and more specifically the under-representation of minority languages and the effects on the related cultures and communities. More than mere access to ICTs, a crucial divide here is the one between 'languages that are 'information rich' and languages that are 'information poor' with regard to online content and services" (Cunliffe \& Herring, 2005, pp. 131-132).

Rooted in the human rights revolution and boosted by the information revolution, accessibility has been leading a movement of its own. The accessibility revolution has been pervading and radically changing the very foundation of our society, bringing access to the fore as a crucial issue in our age, making it "the age of access" (Rifkin, 2001). The revolutionary effects of accessibility are visible in the most divergent aspects of society, meaning that they have also been producing a paradigm shift in various research fields, giving way to novel research methods, and to new models. Clear evidence can be identified in a wide range of fields, from transportation studies to humancomputer interaction, from geography to engineering, from design to sustainability studies, from translation studies to cultural heritage, from education to tourism studies, just to name a few (e.g., Buhalis \& Darcy, 2011; Janelle \& Hodge, 2000; Levine, Grengs, \& Merlin, forthcoming 2019; Litman, 2017; Prodan, 2017; Pullin, 2009; Stephanidis \& Emiliani, 1999). An enumeration and analysis of every case would require a space much longer than the one at my disposal. Briefly mentioning two cases, upon first glance quite distant from AVT and MA, may help outline the revolutionary changes being produced by accessibility. In the area of digital sustainability, accessibility has been playing a key role for quite a long time. Just consider that in both the first and the second edition of the UNESCO General Guidelines to Safeguard Documentary Heritage, the central term of preservation is defined in relation to accessibility, respectively as that which "encompasses all actions required to make documentary heritage accessible for as long as it is required" (Foster, Lyall, Marshall, \& Russel, 1995, p. 76) and "the sum total of the steps necessary to ensure the permanent accessibility of documentary heritage" (Edmondson, 2002, p. 61).Over the last two decades, accessibility has become increasingly more relevant in the field. Acknowledging that the ability to "provide access to digital information is linked to more than technical issues" (Bradley, 2007, p. 156) and that it also includes other factors, such as economic and social ones, researchers have started to develop an entirely new approach to investigate issues of digital sustainability based on accessibility. In turn, this has produced foundational ramifications for the whole field of sustainability studies: since "access concerns can be considered a prerequisite for sustainability", then accessibility is "a necessary step towards conceptualizing the sustainability of human societies and their development" (Prodan, 2017, pp. 67-69). The transformative effects of accessibility are even more pronounced in the case of transportation studies. Accessibility has played an essential role in the field since at least the late 1950s. Over the years, it has grown and become one of its main concepts, to the point that, in the last decade, accessibility has radically altered the very core of transportation studies itself. Under the acknowledgement that people rely on transportation "to travel to work but also to get to school, obtain medical care, attend religious services, shop for basic necessities" (Sanchez \& Brenman, 2007, pp. 1-2), transportation becomes vital 
for human flourishing and human dignity, and as such many scholars have been rethinking the very foundations of the field through the lens of accessibility. They have been highlighting how "[accessibility] changes how we think about and measure transport problems and the scope of solutions that are considered for addressing them. As with the Copernican revolution, this shift changes what we consider the system's centre: traffic-based planning places motor vehicles at the centre, while accessibility-based planning places people at the centre of the transport system" (Litman, 2017, p. 4). Thanks to accessibility, "transportation planning is experiencing a paradigm shift (a fundamental change in how problems are defined and solutions evaluated). This involves a change from traffic-based analysis (...) to mobility-oriented analysis (...) to accessibility-based analysis" (Litman, 2017, p. 4). This foundational shift towards accessibility is having major consequences at number of different levels. It affects not only scholars, who have launched interdisciplinary research programmes aimed at establishing accessibility, but also major international actors, such as the Fédération Internationale de I'Automobile (FIA). In his foreword of the advocacy paper on Accessibility. A Changing Paradigm towards "Mobility for All", the president of the organisation, recognising that "the global commitment to sustainable development goals and their targets mandates us to enable transportation systems that are safe, environmentally sustainable and accessible for everyone", states FIA's role "to support and advocate for inclusive policies that make accessibility a systematic concern in the planning and implementation of transport systems around the world" (Fédération Internationale de l'Automobile, n.d.)"I.

A similar revolutionary effect has led accessibility to become a strategic instrument in the agenda of many international actors for the achievement of some of the most pressing social priorities. This is apparent in numerous policies by international bodies, such as the United Nations, the World Health Organisation, the World Bank, and the OECD. A brief look at some European policies will illustrate this point. A first example is that of the European Commission, in that accessibility is at the core of one of the eight areas of action of the European Disability Strategy 2010-2020 (European Commission, 2010), as well as a specific mandate in the Strategic Implementation Plan on Active and Healthy Ageing (European Commission, 2012), and again, a central issue in the New Framework Strategy for Multilingualism (European Commission, 2005). Probably even more importantly, it is one of the three pillars of the Digital Single Market Strategy (European Commission, 2015), one of the chief programmes of the Commission, and the subject of a specific mandate (the so-called European Accessibility Act) under discussion by the European Parliament since December 2015. A second case in point is that of the Council of Europe, which, for example, puts accessibility at the centre of its policies on governance and trust: e.g. accessibility is a recurring theme in at least twelve of the principles and fourteen of the guidelines set up in the Recommendation on e-democracy (Council of Europe, 2009) and one of the eight principles in the Guidelines for Civil Participation in Political Decision Making (Council of Europe, 2017).

The list of the myriad areas of knowledge and society that have been dramatically altered by accessibility could easily go on for pages. As we will see in the next section, these radical changes are the results of three distinctive shifts produced by the accessibility revolution. 


\section{The three shifts of accessibility}

A closer look at the pervasive growth of accessibility in our society, especially in terms of how accessibility has entered and developed in various research fields, shows that these fields have been experiencing a three-fold shift. The first is that of a shift from particularist accounts to a universalist account of access, the second is a shift from a maker-centred to a user-centred approach, and the third is a shift from reactive to proactive approaches.

The evolution from various particularist accounts to a universalist (or integrated/holistic) account of access means that, while access was previously thought to concern exclusively or mainly specific groups of people, it is now understood to concern all human beings. Accessibility usually entered these fields through an initial focus on a specific group, often, though not always, persons with disabilities. Over time, the focus was progressively widened to include other groups until finally reaching a universal scope. The field of human-computer interaction is a clear example, where, thanks to the dedication of progressive scholars, over the past few decades, accessibility has given rise to the area called "universal access in human-computer interaction" (UAHCl), sometimes shortened to "universal access" (Stephanidis, 2009b). The origins of UAHCI "are to be identified in approaches to accessibility mainly targeted toward providing access to computer-based applications by users with disabilities" (Stephanidis, 2009a, p. 1.1). Over time, $\mathrm{UAHCl}$ expanded its focus to other groups, for instance, the elderly, until finally embracing a universal vision by acknowledging that "accessibility can no longer be considered as a specific problem of people with disabilities [but of] society at large" (Stephanidis \& Emiliani, 1999, p. 22). The shift from particularist accounts to a universalist account is even more evident in MA, originally formed as an academic area of research within the field of AVT, the latter being the "branch of translation studies concerned with the transfer of multimodal and multimedial texts into another language and/or culture" (Pérez-González, 2008, p. 13). The transfer of such texts, for example, a film, is carried out through what in AVT are usually called modalities, e.g., interlingual subtitling. Accessibility fully entered the horizon of AVT thanks to the pioneering work of some scholars (e.g. Díaz Cintas, 2005; Gambier, 2003; Orero, 2004), effectively creating the area referred to as MA. Initially however, MA was positioned as a field concerning exclusively "subtitling for the deaf and the hard of hearing (SDH) and audio description (AD) for the blind and the visually impaired" (Orero, 2004, p. VIII) ${ }^{\mathrm{IV}}$. It was at times expanded to include other modalities, such as audio subtitling and sign language interpreting, though it was still framed as specific for persons with sensory disabilities. Over time, scholars began to shift towards a second account of MA based on the idea that MA concerns not only sensory but also linguistic barriers (Díaz Cintas, 2005; Orero \& Matamala, 2007), to then the universalist account according to which MA concerns access to media products, services, and environments ${ }^{\vee}$ for all persons who cannot, or cannot completely, access them in their original form (Greco, 2016b). Obviously, the shifts described in MA should not be seen as linear in time, for versions of the two particularist accounts can still be found in recent literature, e.g., "media accessibility, i.e. audio description, subtitling for the deaf and hard of hearing and audio subtitling" (Orero, 2012, p. 15) 
and "media accessibility has become a key concept in [AVT], devoted to studying how linguistic and sensory barriers can be overcome to make audiovisual products accessible" (Baños, 2017, p. 485). As will be discussed in section 4, an analysis of this shift and of the current status of MA also provides a clear case of a specific aspect in the dialectics of the emergence of AS, that is, the endogenous force exercised by traditional disciplines.

The changing tide towards a universalist account of accessibility has been interlaced with a second movement, namely, the increasing attention towards users as bearers of valuable knowledge for the investigation of accessibility processes and phenomena as well as their active involvement in the design of accessibility solutions and artefacts ${ }^{\mathrm{V}}$. For years, the dominant attitude was based on a radical version of the so-called maker's knowledge tradition (Greco, Paronitti, Turilli, \& Floridi, 2005; Pérez-Ramos, 1988), according to which maker's knowledge was the only one that mattered (Kraus, 2017). Whether it be policymaking, scholarly research or industrial development, or the creation and production of an audiovisual product, an urban plan of a city or some software, the main assumption was that makers know best and that users had neither place, nor their knowledge any value for the design process (Bruiger, 2017; Fisher, 2016). Artefacts were devised according to the maker's point of view (Pheasant, 1996), or, in the best case scenario, according to the makers' interpretation of users' needs and capabilities (Norman, 2013), with makers giving people "what [they] think they want or need or ought to want" (I. H. Thompson, 2014, p. 79). Over time, this has produced a complex series of gaps between the different stakeholders involved (T. Thompson, 2003), of which the most prominent is the maker-user gap, which places makers and users at opposite ends of the spectrum of creation and production. The wider the gap between the maker and the user, the less probable it is that an artefact is accessible (Ashok \& Jacko, 2009), which in turn may strengthen old ghettoisations of users, or create new ghettos (Greco, 2016a, 2016b). Accessibility has however, challenged the maker-centred and maker-driven approach. In order for artefacts to be fully accessible, the knowledge of users and other stakeholders needs to be fully taken into account in the design system because it is as important as maker's knowledge. A major consequence of the new outlook towards users is the privileged status that reception studies have reached in the fields affected by accessibility. Once more, MA is a good example, as in recent years this area has witnessed a sharp increase in reception studies (e.g., Chmiel \& Mazur, 2016; Di Giovanni, 2018; Eardley-Weaver, 2014; Mangiron, 2016; Perego, Del Missier, \& Stragà, 2018; Pöchhacker, 2018; Romero-Fresco, 2015; Szarkowska \& Jankowska, 2015; Szarkowska, Krejtz, Krejtz, \& Duchowski, 2013; Szarkowska, Krejtz, Pilipczuk, Dutka, \& Kruger, 2016). Actually, the distinctive focus of MA on users has led to the flourishing of reception studies in AVT as well (Di Giovanni \& Gambier, 2018) that is, in the field where MA first originated as an academic area, thus fulfilling Gambier's forecast that it would have been precisely through accessibility that reception studies would come to play a key role in the field of AVT (Gambier, 2006).

While the first two shifts have occurred mainly on an epistemological level, the third shift has taken place on a methodological one. The very acknowledgment of the need to consider accessibility within 
the design process, and that users' knowledge is as important as the maker's, poses questions as to the place of accessibility concerns and of user's knowledge within the process of artefact creation as well as how this knowledge should be acquired and used within that process. The process of design of an artefact can be distinguished in a (series of) ex-ante, in itinere, and ex-post stage(s) (Greco \& Pedone, 2015; Greco, Pedone, Monsellato, Rizzo, \& Spinelli, 2012). When access concerns started popping up onto designers' radar, they were mainly addressed by adopting a reactive approach, that is, through the devising of ex-post solutions, such as specific adaptations or add-ons carried out after the realisation of the artefact (Adams, 2009). Over the years, a vast body of research literature has shown the numerous limitations of ex-post solutions, as e.g. they produce a "loss in functionality [or] provide limited and low-quality access" (Emiliani, 2009, p. 2.6). The shortcomings of reactive approaches have also been apparent to the most diverse actors outside scholarly circles. Just consider that in the guide on the enforcement of and compliance with the Americans with Disability Act published five years after the adoption of that law, the American Bar Association states that "if accessibility is only remembered as an afterthought, or late in the planning/design process, it always becomes less effective for the user, more difficult for the designer/contractor, and more costly for the owner" (Salmen, 2000, p. 231). In some cases, adopting a reactive approach means renouncing accessibility completely, because "it is impossible to 'glue' accessibility onto some of the systems as an afterthought or postmanufacture process" (Vanderheiden, 1998, p. 35). The main reason for the failure or the very limited success of ex-post solutions is that reactive approaches are often based on the paternalistic assumption that "users are victims of poorly designed systems and need to be rescued by designers" (Kaptelinin \& Nardi, 2006, p. 112). While in some cases addressing access at the ex-post or in itinere stages is the only possible way, the nature of accessibility as a proactive principle for the fulfilment of human rights calls for a radical methodological change. It requires a shift from reactive approaches to proactive approaches, the latter entailing "a purposeful effort to build access features into a product as early as possible (e.g., from its conception to design and release)" (Emiliani, 2009, p. 2.6). Adopting a proactive approach does not merely mean moving accessibility concerns from the ex-post to the ex-ante stage of design. It also means "placing the users and potential users at the heart of the development process rather than leaving them as an afterthought where they are left to put up with whatever has been designed on their behalf" (Taylor, Caiafa, \& Brown, 2002, p. 257). Indeed, within this shift, accessibility has underscored the fact that all stakeholders must be proactively involved in the design process, thus calling for an "agency distribution" among the different actors involved (Vardouli, 2015). This shift obviously demonstrates that there is no accessibility without participation, and it highlights yet another case of the complex series of gaps between the stakeholders mentioned above, namely the maker-expert-user gap. As such, it is crucial to involve, from the ex-ante stage, not only users but also experts. The ex-post solutions and involvement of experts is a well-known problem in the area of web accessibility, where "a main factor for the lack of Accessibility at the Web is the major knowledge gap that normally exists between developers and Accessibility specialists [as well as the] common practice to consider Accessibility at the very last stages of the development process, or when applications are already coded" (Martín, Cechich, \& Rossi, 2011, p. 7). Over the years, this awareness has pushed researchers as well as industry to devise a series 
of specific methodologies that place accessibility concerns, users and experts at the early stages of development of web applications. An even more conspicuous case comes from the audiovisual industry, where accessibility has been relegated to the ex-post stage for decades. Subtitling, audio description, and dubbing, for example, do not form an integral part of the production process of an audiovisual product, as they are often left to be dealt with at the distribution phase, with two major consequences. These include the implementation of accessibility solutions that are not always efficacious as well as, in some striking cases, a total alteration of the original artistic intention of the creators or aesthetic features of the audiovisual product (Romero-Fresco, 2013). While this attitude nowadays is still dominant, one of the first signs of a growing awareness towards a shift from a reactive to a proactive approach in this context can be found in The Arts and 504: a 504 Handbook for Accessible Arts Programming. First published by the National Endowment for the Arts in 1985, the handbook is addressed to projects and activities requesting funding from the agency, and it contains a series of best practices and suggestions for compliance with section 504 of the Rehabilitation Act of 1973. The section on captioning of the 1992 version of the handbook includes an extra explanatory paragraph, not present in the first edition, which states that "captioning film is most effective if taken into account at the earliest stage of production so that consideration can be made for technical concerns and length of dialogue" (National Endowment for the Arts, 1992, p. 79). It is precisely this awareness that, in recent years in the field of MA, has driven the development of an approach called accessible filmmaking (AFM). The focus on moving accessibility from the ex-post to the ex-ante stage of film production has led AFM to explicitly address and bridge the maker-expert-user gap by introducing the role of the director of accessibility, an MA expert involved from the very start of the creation of an audiovisual product (Branson, 2018). Finally, over the past few years, the area of $A D$ has proven to be very fertile ground for the intersection and the flourishing of the three shifts, producing some of the most innovative projects in MA, e.g. from participatory AD in opera events (Di Giovanni, 2018) to enriched descriptive guides in museums (Neves, 2016) to integrated AD in theatre performances (Fryer, 2018). They all share the same traits: a universalistic account of accessibility, the implementation of a proactive approach, and the involvement of the different stakeholders during the various stages of the life-cycle of production. Their ability to embrace all the salient features of accessibility and to put them into practice with a conscious, socially-engaged attitude can point the way towards a more structural and analytical approach of AS to many other areas.

\section{Internal and external forces in the formation of accessibility studies}

Research on knowledge production and organisation usually assumes that, in order for a new field to be born, one strong, yet not necessarily well-defined, "unique, or at least central, concern" must exist (Pietig, 1984, p. 368), which then sets in motion a dialectic between endogenous and exogenous forces that may lead to the formation of the new field (Farjoun, 2002). While scholars have been debating the precise list of mechanisms and their features for decades, 
there is widespread agreement on several of them: (a) interdisciplinarity, (b) the formation of a research community, and (c) forms of opposition by well-established fields.

When a new problem enters the knowledge horizon, if it cannot be tackled using exclusively the tools of a specific field, a common practice among researchers is to join forces and set up a multidisciplinary programme, with each one utilising ideas and methods from her own discipline, and then "split apart unchanged when the work is done" (Committee on Facilitating Interdisciplinary Research, National Academy of Sciences, National Academy of Engineering, \& Institute of Medicine, 2005 , p. 29). That is, multidisciplinary research is additive, not integrative (Klein, 1990). Some issues are so ground-breaking and interwoven with social questions that they "demand interdisciplinary participation" and prompt "scientists, engineers, social scientists, and humanists to join" forces (Committee on Facilitating Interdisciplinary Research et al., 2005, p. 17). The mere juxtaposition of different fields is not sufficient to address those issues; rather, it is necessary to choose the path of the "integration and synthesis of ideas and methods" (Committee on Facilitating Interdisciplinary Research et al., 2005, p. 27), a path that often leads to the creation of "new hybrid research fields" (Committee on Facilitating Interdisciplinary Research et al., 2005, p. 18). Through a process refined over decades, accessibility issues have proven to demand such an interdisciplinary approach, pulling together researchers from the most diverse of fields from engineering to translation, from cultural heritage to architecture, from computing to transportation - and pushing them to share their knowledge and tools to devise new methods and techniques in order to address the intricate nature of access problems. Game accessibility VII is a fast-growing topic in MA. Initially framed in terms of translation problems requiring a multidisciplinary approach, in recent years scholars have convincingly shown that the topic is much broader and indeed has an "inherently interdisciplinary nature" (O'Hagan \& Mangiron, 2013, p. 37). Mangiron's (2011) call for interdisciplinarity as a strategy for the future growth of research on the topic has become reality in just a few short years, for game accessibility is now addressed through a series of interdisciplinary approaches that involve a large number of fields. These include the ones she identified as well many more, such as: computer engineering, AVT, psychology, and healthcare, but also media studies, anthropology, sociology, cultural studies, and humancomputer-interaction (O'Hagan \& Mangiron, 2013). Even if we narrow our focus to issues specifically related to disability and technology, that is, even if a particularist account is assumed, researchers are now claiming that this "complex interplay (...) can best be understood by recourse to interdisciplinary and international evidence" (Roulstone, 2016, p. 5), which has led to the formation of "interdisciplinary teams of researchers and practitioners [who are] embracing holistic perspectives on disabled people's intersection with technology to include psycho-social constructs and their connection to technological and social opportunity" (Roulstone, 2016, p. 99).

The attraction of accessibility as a unique idea, together with the need to combine efforts to develop interdisciplinary resources, has been pulling researchers out of the sphere of influence of traditional fields and bringing them together, in accordance with the formation of the so-called invisible colleges (Crane, 1972). They have been creating an informal network, structurally grounded on shared 
research interests based on a common subject matter, and socially bonded through a communication grid on national and international scales (Bakker, 2017; Price, 1963). This process is brilliantly summarised by Holmes in his seminal paper, published in 1972, in which he argues in favour of translation studies as a new, distinctive field:

As a new problem or set of problems comes into view in the world of learning, there is an influx of researches [sic] from adjacent areas, bringing with them the paradigms and models that have proved fruitful in their own fields. These paradigms and models are then brought to bear on the new problem, with one of two results. In some situations the problem proves amenable to explicitation, analysis, explication, and at least partial solution within the bounds of one of the paradigms or models, and in that case it is annexed as a legitimate branch of an established field of study. In other situations the paradigms or models fail to produce sufficient results, and researches [sic] become aware that new methods are needed to approach the problem. In this second type of situation, the result is a tension between researches [sic] investigating the new problem and colleagues in their former fields, and this tension can gradually lead to the establishment of new channels of communication and the development of what has been called a new disciplinary utopia, that is, a new sense of a shared interest in a common set of problems, approaches, and objectives on the part of a new grouping of researches [sic]. (Holmes, 1988, p. 67) ${ }^{\mathrm{VIII}}$.

Over the course of its diffusion across many fields, access issues have been attracting an increasingly broader range of researchers, who share both a common interest as well as a willingness to hybridise their knowledge and methods in order to address those issues. Over the years, they have acquired new skills that do not fully conform to a single, specific area of the current system, as they no longer fit within classical disciplinary boundaries. They end up having more in common amongst themselves - in Holmes' words, sharing the same "new disciplinary utopia" - than with colleagues from their original fields. The area of MA is a clear case. Though it was bred within the field of translation studies, in recent years MA problems have attracted scholars from the most vastly divergent fields, thanks in large part to a favourable environment facilitated by many international and interdisciplinary research projects. Researchers and practitioners from engineering to psychology, from filmmaking to computer science, from tourism studies to the performing arts, have been joining forces in order to tackle MA problems, sharing their own disciplinary methods and creating new ones along the way. During this process they have been slowly moving beyond the boundaries of their original fields, detaching themselves from their colleagues, and forming a new community of peers, a division of the invisible college of AS. The peculiarities of MA as an area that can be neither merely nor entirely "annexed as a legitimate branch of an established field of study" are already leading MA scholars to debate fundamental internal issues, such as the forms of training and education that should be devised in order to adequately respond to the novel character of the field (Chmiel, Vercauteren, \& Mazur, forthcoming). 
While the formation of a new community around accessibility and the joint development of interdisciplinary methods have been acting as exogenous forces and bringing together researchers towards the common ground of AS, they have been opposed by endogenous forces trying to bar that very process. Seeing as "no discipline willingly abdicates its mandated sovereignty" (Klein, 2009, p. 271), well-established fields tend to resist the formation of a new field, perceived as a competitor or a threat to their fiefdoms, by expressing a cultural stance that some call scholasticism (Floridi, 2002). They tend to shield themselves behind the walls of their orthodoxy, so that their "response is often only to create new subfields - a seemingly endless proliferation that incorporates members of the emerging community of scholars within the larger enterprise without any debate about the significance of their challenge" (Salter \& Hearn, 1996, p. 154). A good example of how scholasticism has been cropping up in the development of AS is once again provided by MA and translation studies, where the latter has manifested its "sheer force of orthodoxy" (Klein, 2009, p. 271) in at least two main ways. The first one is the attempt to keep MA within the disciplinary boundaries of translation studies, while the second one is the apparently positive claim that MA may be an autonomous field of its own.

As we have seen in the previous section, MA was born within the field of translation studies, specifically as an area of AVT. The initial definition of MA was based on a particularist account that considered $M A$ to be exclusively concerned with $S D H$ and $A D$, with some variants extending it to other modalities like audio subtitling and sign language interpreting. However, all these alternatives still frame MA in relation to persons with sensory disabilities. Over time, scholars began to adopt a second particularist account, which expanded the scope of MA to include foreign language speakers in addition to persons with sensory disabilities. While the first particularist account frames MA as a sub-area of AVT, the second particularist account makes it overlap with AVT itself. Common to both particularist accounts is that they position MA within the disciplinary borders of translation studies. In addition, both implement forms of resistance by relegating MA problems to the realm of translation problems. Yet, the moment AVT problems are positioned in terms of accessibility, we are stepping outside the safe, familiar boundaries of translation studies and treading upon broader ground, where translation is just one of the many factors at play, and often not the main one (Romero-Fresco, 2018). This being said, endorsing the two particularist accounts may lead to some controversial implications. Grounding MA within translation means paring down its scope to a narrower set of so-called modalities (or services), the ones that are translation based, and excluding from MA others that do not involve any translation activity, or perhaps only in a limited way. Even if a restrictive definition of MA was taken, that is, to include only translation-based MA services for the group of persons with sensory disabilities, this still creates friction with the widespread interpretation of MA services for that specific group as adopted by many scholars as well as by industry, service providers, and international bodies and organisations (e.g., Armstrong, 2016; Cappello, 2014; Ellis \& Goggin, 2015; European Telecommunications Standards Institute, 2009; Focus Group on Audiovisual Media Accessibility, 2013; NEM-ACCESS, 2016; SENSE, 2006; Shirley \& Kendrick, 2006; Slater, Lindstrom, \& Astbrink, 2010; Utray, de Castro, Moreno, \& Ruiz-Mezcua, 2012; Varney, 2013). Both scholars and organisations 
identify subtitles for the deaf and hard of hearing, audio description, sign language interpreting, and clean audio as MA services specific for persons with sensory disabilities ${ }^{\mathrm{IX}}$. While translationbased activities do play a key role, albeit it is not always an exclusive one, in the former three services, the latter - clean audio - does not involve any form of translation (Jankowska, forthcoming). This creates discord between the two versions of MA services, even though both are based on the first particularist account that limits MA to persons with sensory disabilities. Even more contentious is the implication of the second particularist account, which limits MA to sensory and linguistic barriers. A direct consequence is the exclusion from the core interests of MA of any person who does not fall within the groups identified by those parameters. It follows therefore, that children, the elderly, and persons with cognitive disabilities, for example, as well as any service that makes media artefacts accessible to them, are thus excluded from the visible horizon of MA. Any effect of (linguistic or sensory) MA services on them can be determined a mere positive externality (Brown, 2010-2011) or the result of a spillover effect (Committee on Disability in America \& Institute of Medicine, 2007), not a planned result. Hence, by framing MA in terms of specific groups, or services for specific groups, the universal trait of accessibility is betrayed, inadvertently re-creating a ghetto effect (Greco, 2016a, 2016b). Furthermore, a second form of opposition is apparent with regards to the notion that MA be regarded as "media accessibility studies", that is, that we should consider MA to be a full-fledged academic field of its own, one that incorporates AVT, hence, disregarding the need to talk about AS. Yet, in order to claim that MA is a field of its own, one has to accept all the mechanisms that justify the rise of AS presented in the previous two sections while also demonstrating that those mechanisms apply exclusively to AVT/MA, and not to any other fields. While it does acknowledge that MA has increased the number of shareholders, this claim seems to want to maintain the control stock in the hands of translation studies by allocating a dominant role to translation practices.

The universal account of MA successfully disentangles itself from the abovementioned controversies while also highlighting the benefits of not restricting the focus of MA to any specific group of users or list of access services. Rather, it allows for the assumption of functional processes resulting from the interaction between users' specificities and the means to address those specificities in terms of accessing either media artefacts or other artefacts through media means. By making translation neither the sole nor the main driving force behind MA but simply one of the many factors that contribute to address accessibility issues, the universal account of MA allows for the inclusion of other groups and access services, favours the convergence of the different conceptions of MA and MA services developed in other fields, and encourages the design of solutions that are more inclusive (Jankowska, 2017, forthcoming; Romero-Fresco, forthcoming). MA is wider than AVT and cannot be merely reduced to a sub-area of TS. It is a broader, interdisciplinary area, that criss-crosses many well-established fields, including translation studies and AVT. However, it cannot be entirely and exclusively reduced to any of them, because its true nature is that of being an area within the field of AS. An example may help illustrate this point. As said above, over the last few years, some filmmakers and MA scholars have been developing and implementing a new approach called AFM. According to the original definition, AFM is "the integration of AVT 
and accessibility as part of the filmmaking process" (Romero-Fresco, 2013, p. 203), which includes "not only accessibility for people with sensory impairments but also, in a wider sense, translation or linguistic accessibility; in other words, making film accessible to viewers with hearing/visual loss and to viewers in other languages" (Romero-Fresco, 2013, p. 223). However, this initial statement of AFM presented two main limitations: (a) it framed AFM within the second particularist account of MA by restricting its scope to those with sensory and linguistic barriers, and (b) it lacked a strong focus on the proactive role of users. Explicitly embracing the rise of AS (Romero-Fresco, 2017b), over the past years AFM has moved beyond the particularist account by adopting a new definition that fully complies with the universalist account of MA. More specifically, the new definition states that AFM concerns how to "make a film accessible to people that cannot, or cannot properly, access it in its original form" (Romero-Fresco, 2017a) which mirrors the very definition of the universalist account of MA (Greco, 2016b) discussed in the previous pages. Moreover, AFM has also implemented a user-centred approach, whereby users are not merely passive recipients of, but active agents in, the process of production of accessible audiovisual media (Dangerfield, 2017, 2018). Finally, as we already saw, it has framed its methodology in terms of the maker-expert-user gap (Branson, 2018; Branson \& Romero-Fresco, 2017). As a result, AFM has been able to display its traits by modifying itself according to the universal account of accessibility. Consequently, AFM can no longer be considered an internal approach of AVT nor of a particularist account of MA, but as applied AS within the universalist account of MA.

\section{What is accessibility studies?}

Through the multifaceted process summarised in the previous sections, accessibility has slowly but steadily entered a variety of very different fields, moving its way to the forefront and becoming one of their most fruitful concepts. It has produced a wealth of new methods and models, created radical change in the foundations of many fields, and has given rise to new areas that have been gradually converging to constitute the wider field of AS. As I have mentioned in section 2, this process can be clearly identified in a number of differing areas. In all of them as well as in society at large, accessibility has driven theoretical, methodological, and social innovation, leading to the development of thriving research programmes and the implementation of novel practices, and, as stated above, has often even provided a new foundation for those very fields. This multidimensional and multifaceted process has been leading to the formation of accessibility studies, the research field concerned with the critical investigation of accessibility processes and phenomena, and the design, implementation and evaluation of accessibility-based and accessibility-oriented methodologies.

Accessibility refers to neither the prima facie meaning of access as "having entrance to a system, goods and services" nor to the availability of the means or opportunities for "having entrance to" (Shadid, Prins, \& Mas, 1982), meaning that it implies more than the possibility to reach or have "direct access or access through add-on" solutions (Stephanidis \& Salvendy, 1998, p. 112; 
see also Vanderheiden, 1990). As acknowledged in the field of digital sustainability, "[access] is not only about the ability to find and retrieve an item, but also the ability to use, view, listen to, interact with, display, or run the digital item in such a way that users can be assured that what they are viewing satisfies their needs" (Bradley, 2007, p. 154). Therefore, accessibility lies at the heart of a whole range of issues, such as acceptability, adaptability, availability, flexibility, personalisation, and usability. The character of access as a necessary requirement, as discussed in this paper, makes it a concept more primitive, "systematically and logically prior, more basic and more fundamental" (Jammer, 1999, p. 6), from which others can be obtained as derived concepts. This is why, among the many names suggested for this new field, AS is the most suitable one. The fact that accessibility encompasses a multiplicity of other concerns highlights a crucial point concerning the second part of the definition of AS. If we adopt Gibson's theory of affordances (Gibson, 1979) ${ }^{X}$ and read it through the lens of accessibility, we can interpret an artefact as a complex of disabling constraints and enabling affordances. Then, the relationship between an artefact and a user can be analysed in terms of a conditioning friction. The less the design process is based on accessibility methodologies, the higher the probability of producing artefacts with a greater number of disabling constraints and fewer enabling affordances. This leads to a higher probability of a friction, between the artefact and the user, conditioning the space of action and knowledge of the user. On the other hand, the more the design process is based on such methodologies, the higher the probability of producing artefacts with a greater number of enabling affordances and fewer disabling constraints, and thus, the lower the probability of a conditioning friction between the artefact and the user. In order to produce artefacts of the latter kind, the design process need to be carried out in accordance with the general methodological approach delineated by the three shifts analysed in the previous pages. The three shifts define the normative boundaries of epistemic and moral action: this general methodological stance of AS allows us not only to design and implement new artefacts that foster inclusion, but also to investigate and evaluate all the other artefacts, and come up with strategies of intervention. Moreover, if we consider that "user" does not stand for some remote and amorphous figure, but rather, has to be understood within the variations of human diversity and capabilities (Sen, 1985), we can appreciate the breadth of AS. In addition, one can also make out some preliminary traits of a possible ethical and social theory that could be developed within this field: a theory that promotes the explicit design of artefacts for the well-being of human beings and the promotion of social justice and epistemic justice (Fricker, 2007).

Before concluding by briefly looking at what lies ahead of and for AS, a few steps back to the origins of the field may help. Even though AS has emerged as a research field only in recent years, its foundation indeed goes back to the ideas and work of Otto Neurath. Among his contributions we can find many of the features of AS, e.g. access as a foundational idea for human dignity, an interdisciplinarity methodology, the devising of new methods, the importance of users and of their knowledge, and the involvement of experts and of different stakeholders in the design process. Infused by the spirit of logical positivism, being himself one of the founding and prominent members of the Vienna Circle, Neurath was convinced that access to knowledge was fundamental for empowering people, especially the most vulnerable (see O. Neurath, 1973c), because only 
through access to knowledge they "could develop their judgement and become active citizens of a democratic society" (M. Neurath, 1946). Between the 1910s and the 1920s, Neurath began to work on a method for the visualisation of information, initially called the "Vienna method", in order to "represent social facts pictorially" (O. Neurath in Burke, 2009, p. 211). In 1925, he established the Social and Economic Museum in Vienna, ${ }^{\mathrm{XI}}$ where he implemented his method more analytically. The main goal of the museum was to make knowledge and social facts "within reach of everybody" (O. Neurath, 1973d, p. 230). Neurath's museum adopted a mix of instruments and new technologies, including early experiments with animated films, which, through the use of his method, made statistical data, facts, and information about the various aspects of social life and of the world accessible to the general population. The work was realised by a truly interdisciplinary team comprising "the director, two transformers, two chief artists, and a number of technicians skilled in the work process [as well as] experts in statistics, history, medicine, cartography, geography, engineering, industrial management, history of art, etc." (M. Neurath, 1974, p. 137). The key figure was an expert called "the transformer", a seminal version of the accessibility expert, whose tasks included "to understand the data, to get all necessary information from the experts, to decide what is worth transmitting to the public, how to make it understandable, how to link it with general knowledge or with information already given in other charts" (M. Neurath \& Kinross, 2009, p. 78). This role was usually carried out by Marie Neurath ${ }^{\mathrm{XII}}$, according to whom "the transformer is the trustee of the public" (M. Neurath \& Kinross, 2009, p. 78). Over the years, the Neuraths refined and expanded upon the method, renaming it "International system of typographic picture education" (Isotype). They exported it from New York to Moscow to Nigeria, and applied it to a vast range of media, replicating the same work method over and over again. A few examples may better illustrate the vast scope of their contribution. Their work on children's books was tested with experiments performed in schools and, through collaboration with C.K. Ogden, the inventor of Basic English, they also produced two texts that combined Isotype with Basic English, constituting an early case, if not the very first, of easy reading. In 1941, they were contacted by Paul Rotha, a pioneer of British documentary filmmaking, who saw in the Isotype method a way to make his films more accessible to a wider audience. Once again, the Neuraths replicated the same organisational model they developed in Vienna, with the transformer working in close contact with the different departments of the filmmaking process, from the director to the scriptwriter, sometimes "already at the first stages of conception" (M. Neurath \& Kinross, 2009, p. 61), which probably makes this the first explicit case of $A F M^{X I I I}$. The importance of the active participation of the users in the design process is exemplified by Otto Neurath's consultancy to the Bilston Borough Council in 1945. When discussing a plan to relocate a part of the population to new houses in other areas, Neurath underlined that "participation is vital. The whole success of any plan involving the lives of human beings depends upon obtaining the assent, encouragement, and co-operation of those human beings" (O. Neurath, 1973a, p. 76). These are just a few examples of the richness of Neurath's visionary work. He believed that the idea of a democratic polity founded on human dignity and fraternity, like "the distant island of Atlantis" and other great utopias, are constructions of "social engineering" (O. Neurath, 1973b, p. 151) that take on "the task of consciously cultivating 
the future and the possible" (O. Neurath, 1973b, p. 155). He saw making knowledge accessible to everyone as fundamentally functional towards making possible the utopia of a democratic future possible.

\section{Conclusion: the future commitments of the early days}

Human beings have been successfully adapting to technology for a very long time (Norman, 2013). Nonetheless, as we have seen, ICTs are creating a new environment and are reshaping access. This is a process that, if not vigilantly supervised and guided, will risk producing new, deep-seated forms of discrimination whilst exacerbating old ones, because reshaping access means reshaping the very conditions for human dignity. We are epistemic agents and our lives unfold in a knowledge space(s). Yet, this space has become a breeding ground of social injustice through epistemic injustice: new forms of discrimination based on who can get access and who can't. All these has been making access "a conceptual tool for rethinking our world-view as well as our economic view, making it the single most powerful metaphor of the coming age" (Rifkin, 2001, p. 15). Within this context, AS is a timely field that, through critical investigation and proactive agency, addresses some of the most pressing issues our society is facing, and will face. A field within which it is also possible to develop an ethical and social perspective that promotes a culture of (social, ethical, political, scientific, technological, etc.) design in order to render our world an environment with less disabling constraints and more enabling affordances. What lies ahead of us is a highly-demanding task: to accept our role as the trustees of the public, to cultivate the utopia of a just and inclusive society, and to work to make it possible despite difficulties and uncertainties we may face, as brilliantly expressed once again by Calvino:

The Great Khan's atlas contains also the maps of the promised lands visited in thought but not yet discovered or founded: New Atlantis, Utopia, the City of the Sun, Oceana, Tamoe, New Harmony, New Lanark, Icaria.

Kublai asked Marco: 'You, who go about exploring and who see signs, can tell me toward which of these futures the favoring winds are driving us.'

'For these ports I could not draw a route on the map or set a date for the landing. At times all I need is a brief glimpse, an opening in the midst of an incongruous landscape, a glint of lights in the fog, the dialogue of two passersby meeting in the crowd, and I think that, setting out from there, I will put together, piece by piece, the perfect city, made of fragments mixed with the rest, of instants separated by intervals, of signals one sends out, not knowing who receives them. If I tell you that the city toward which my journey tends is discontinuous in space and time, now scattered, now more condensed, you must not believe the search for it can stop. (Calvino, 1974, p. 164) XIV $^{2}$

MA was born thanks to the pioneering work of some scholars who envisioned the fundamental traits of accessibility. Over the past two decades, MA has been gradually growing into a vast and lively 
community of deeply-committed scholars, whose work has been advancing the critical role of accessibility in our society. As one of the most mature areas in which the process of the formation of AS has been taking place, what lies ahead of MA is a task as exciting as it is challenging: to fully embrace its identity as an area within AS. By working towards making visible the invisible college of AS, of which they are among its founding and more engaged members, MA scholars can let AS fulfil its role as a force for critical reflection and a driver for social change.

\section{Acknowledgements}

The present paper is part of a series of texts on AS that have been keeping me company for a very long time. I am grateful to the editorial board of the Journal of Audiovisual Translation for the invitation to publish this paper in its inaugural issue and to the two anonymous referees for their comments. I introduced the term accessibility studies and discussed the ideas presented in this paper during so many talks I have delivered since 2012 that listing them all would require a space longer than this very paper. My most sincere thanks to all the participants of those meetings for their feedback. I will mention only a few as representatives of all. I introduced an early version of section 3 at the ArtLab13 conference held on 24-28 June 2013. An early version of section 2 and 6 were debuted at the seminar Expo 2015 per l'Italia held in Martina Franca (Italy) on 3 December 2013, co-organised by CENSIS and the Italian Pavilion at Expo 2015. A revised version of section 2 and 6 were also presented at the Zerobarriere conference held in Matera (Italy) on 2728 September 2014 as part of the candidacy of the city of Matera as European Capital of Culture 2019 (which then was awarded the title), co-organised by the Comune di Matera, the European Network for Accessible Tourism, Design for All Europe, the Council of Europe, and many others. I delivered the first complete presentation of sections 1-5 at the conference The Future of Media Accessibility: Issues and Visions held in Lecce (Italy) on 26-27 June 2017. A version of sections 2, 5 and 6 was presented at the TransAccess conference held in Krakow on 16 November 2017, coorganised by the DG Translation of the European Commission and the Chair for Translation Studies and Intercultural Communication of the Jagiellonian University in Krakow (Poland). I wish to thank for their kind invitation in the aforementioned meetings: Dino Angelaccio, Ugo Bacchella, Ivana Bosso, Valentina Curato, Anna Jankowska, Pete Kercher, Krzysztof Łoboda, Francesco Maietta, Simona Martini, Maria Piotrowska. Numerous discussions with Josh Branson, Kate Dangerfield, Louise Fryer, Anna Jankowska, Pablo Romero-Fresco, and Davide Ruggieri have helped me refine my ideas in a profound way. With Anna Jankowska and Pablo Romero-Fresco in particular I am in far greater debt. Our long conversations and their constant support are a rare gift. They have helped me sharpen my thought and provided support and encouragement in ways beyond any professional level; most likely, this paper would have not seen the light of day without their support. Teressa Canosa skilfully copyedited the last version of this paper. All remaining mistakes are mine. 


\section{Biographical note}

Gian Maria Greco, PhD, is Marie Skłodowska-Curie Individual Fellow and a member of the TransMedia Catalonia Research Group at the Universitat Autònoma de Barcelona (Spain), where he directs the project UMAQ. He is Research Associate at GALMA, Universidade de Vigo (Spain). His research focuses on the theoretical foundation of accessibility studies and how it relates to human rights, the media, and the performing arts.

\section{References}

Adams, R. (2009). User modeling: A universal access perspective. In C. Stephanidis (Ed.), The universal access handbook (pp. 24.1-24.19). Boca Raton, FL: CRC Press.

Armstrong, M. (2016). From clean audio to object based broadcasting (White Paper WHP324). London: BBC. Retrieved from http://downloads.bbc.co.uk/rd/pubs/whp/whp-pdffiles/WHP324.pdf

Ashok, M., \& Jacko, J. A. (2009). Dimensions of user diversity. In C. Stephanidis (Ed.), The universal access handbook (pp. 4.1-4.15). Boca Raton, FL: CRC Press.

Bakker, J. I. (2017). Scientific networks and invisible colleges. In G. Ritzer (Ed.), The Blackwell encyclopedia of sociology (pp. 4115-4116). Oxford, United Kingdom: Blackwell.

Baños, R. (2017). Audiovisual translation. In K. Bedijs \& C. Maaß (Eds.), Manual of romance languages in the media (pp. 471-488). Berlin, Germany: De Gruyter.

Bradley, K. (2007). Defining digital sustainability. Library Trends, 56(1), 148-163.

Branson, J. (2018, June). Bridging the maker-user gap: the case of the Italian short film Acquario. Paper presented at the Conference on Understanding Quality in Media Accessibility, Barcelona, Spain.

Branson, J., \& Romero-Fresco, P. (2017, October). Bringing media accessibility in from the cold: A comparative analysis of collaborative and standard approaches to $A D$ and SDH. Paper presented at the Conference on Accessibility in Film, Television and Interactive Media, York, United Kingdom.

Brown, C. B. (2010-2011). Incorporating third-party benefits into the cost-benefit calculus of reasonable accommodation. Virginia Journal of Social Policy and the Law, 18, 319-344.

Bruiger, D. (2017). The found and the made. New York, NY: Routledge.

Buhalis, D., \& Darcy, S. (2011). Introduction: From disabled tourists to accessible tourism. In D. Buhalis \& S. Darcy (Eds.), Accessible tourism: Concepts and issues (pp. 1-20). Bristol, United Kingdom: Channel View Publications.

Buitenweg, R. (2007). Human rights, human plights in a global village. Atlanta, GA: Clarity Press.

Burke, C. (2009). Isotype: representing social facts pictorially. Information Design Journal, 17(3), 211-223.

Burke, C. (2013). Animated Isotype on film. 1941-7. In C. Burke, E. Kindel, \& S. Walker (Eds.), Isotype. Design and contexts: 1925-1971 (pp. 366-389). London, United Kingdom: Hyphen Press. 
Calvino, I. (1974). Invisible cities (W. Weaver, Trans.). Orlando, FL: A Harvest Book, Harcourt, Inc.

Cappello, M. (Ed.) (2014). Enabling access to the media for all. Strasbourg, France: European Audiovisual Observatory.

Chmiel, A., \& Mazur, I. (2016). Researching preferences of audio description users. Limitations and solutions. Across Languages and Cultures, 17(2), 271-288.

Chmiel, A., Vercauteren, G., \& Mazur, I. (Eds.). (forthcoming). Media accessibility training. Special issue of Linguistica Anteverpiensa.

Committee on Disability in America, \& Institute of Medicine. (2007). The future of disability in america (M. J. Field \& A. M. Jette Eds.). Washington, DC: National Academies Press.

Committee on Facilitating Interdisciplinary Research, National Academy of Sciences, National Academy of Engineering, \& Institute of Medicine. (2005). Facilitating interdisciplinary research. Washington, DC: The National Academies Press.

Council of Europe. (2009). Recommendation CM/Rec(2009)1 of the Committee of Ministers to member states on electronic democracy (e-democracy). CM/Rec(2009)1.

Council of Europe. (2017). Guidelines for civil participation in political decision making. CM(2017)83final.

Crane, D. (1972). Invisible colleges: Diffusion of knowledge in scientific communities. Chicago, IL: The University of Chicago Press.

Cunliffe, D., \& Herring, S. C. (2005). Introduction to minority languages, multimedia and the web. New Review of Hypermedia and Multimedia, 11(2), 131-137.

Dangerfield, K. (2017, October). The accessible film project. Paper presented at the Conference on Accessibility in Film, Television and Interactive Media, York, United Kingdom.

Dangerfield, K. (2018, June). The value of difference in media accessibility quality. Paper presented at the Conference on Understanding Quality in Media Accessibility, Barcelona, Spain.

Di Giovanni, E. (2018). Audio description for live performances and audience participation. The Journal of Specialised Translation, (29), 189-211.

Di Giovanni, E., \& Gambier, Y. (2018). Introduction. In E. Di Giovanni \& Y. Gambier (Eds.), Reception studies and audiovisual translation (pp. VII-XII). Amsterdam, Netherlands: John Benjamins.

Díaz Cintas, J. (2005). Audiovisual translation today. A question of accessibility for all. Translating Today, 4, 3-5.

Dutton, W. H. (2004). Social transformation in an information society: rethinking access to you and the world. Paris, France: UNESCO.

Eardley-Weaver, S. (2014). Lifting the curtain on opera translation and accessibility. Translating opera for audiences with varying sensory ability (Unpublished doctoral dissertation). Durham University, Durham, United Kingdom. Retrieved from http://etheses.dur.ac.uk/10590/1/Sarah_Eardley-Weaver_PhD_thesis.pdf

Edmondson, R. (2002). Memory of the world: General guidelines to safeguard documentary heritage (Revised edition 2002 ed.). Paris, France: UNESCO.

Ellis, K., \& Goggin, G. (2015). Disability and the media. London, United Kingdom; New York, NY: Palgrave Macmillan. 
Emiliani, P. L. (2009). Perspectives on accessibility: From assistive technologies to universal access and design for all. In C. Stephanidis (Ed.), The universal access handbook (pp. 2.1-2.18). Boca Raton, FL: CRC Press.

European Commission. (2005). A new framework strategy for multilingualism. COM(2005)596 final.

European Commission. (2010). European disability strategy 2010-2020: A renewed commitment to a barrier-free Europe. $\operatorname{COM(2010)0636~final.~}$

European Commission. (2012). Taking forward the strategic implementation plan of the European innovation partnership on active and healthy ageing. $\operatorname{COM(2012)83~final.~}$

European Commission. (2015). A digital single market strategy for europe. COM(2015)192 final.

European Telecommunications Standards Institute. (2009). Digital video broadcasting (DVB): Specification for the use of video and audio coding in broadcasting applications based on the MPEG-2 transport stream (Vol. RTS/JTC-DVB-258). Sophia Antipolis, France: European Telecommunications Standards Institute.

Farjoun, M. (2002). The dialectics of institutional development in emerging and turbulent fields: The history of pricing conventions in the on-line database industry. The Academy of Management Journal, 45(5), 848-874.

Fédération Internationale de l'Automobile. (n.d.). Accessibility. A changing paradigm towards "mobility for all". Paris, France: Fédération Internationale de l'Automobile.

Fisher, S. (2016). Philosophy of architecture. In E. N. Zalta (Ed.), The Stanford encyclopedia of philosophy (Wint. 2016 ed.). Stanford, CA: Metaphysics Research Lab, Stanford University. Retrieved from https://plato.stanford.edu/archives/win2016/entries/architecture

Floridi, L. (2002). What is the philosophy of information? Metaphilosophy, 33(1-2), 123-145.

Floridi, L. (2015). Introduction. In L. Floridi (Ed.), The online manifesto. Being human in a hyperconnected era (pp. 1-3). Cham, Switzerland: Springer.

Focus Group on Audiovisual Media Accessibility. (2013). Final report of activities: Working group C "Visual signing and sign language" and D "Emerging access services" on common topics. Geneva, Switzerland: International Telecommunication Union.

Foster, S., Lyall, J., Marshall, D., \& Russel, R. (1995). Memory of the world: General guidelines to safeguard documentary heritage. Paris, France: UNESCO.

Foucault, M. (2007). Security, territory, population. Lectures at the Collège de France, 1977-78. New York, NY: Palgrave Macmillan.

Francioni, F. (2007). The rights of access to justice under customary international law. In F. Francioni (Ed.), Access to justice as a human right (pp. 1-55). Oxford, United Kingdom: Oxford University Press.

Fricker, M. (2007). Epistemic injustice. Power and the ethics of knowing. Oxford, United Kingdom: Oxford University Press.

Fryer, L. (2013). Putting it into words: The impact of visual impairment on perception, experience and presence (Unpublished doctoral dissertation). Goldsmiths College, University of London, London, United Kingdom. Retrieved from http://research.gold.ac.uk/10152/1/PSY_thesis_Fryer_2013.pdf 
Fryer, L. (2018). Staging the audio describer: An exploration of integrated audio description. Disability Studies Quarterly, 38(3). Retrieved from http://dsqsds.org/article/view/6490/5093

Gambier, Y. (2003). Introduction. Screen transadaptation: Perception and reception. The Translator, 9(2), 171-189.

Gambier, Y. (2006). Multimodality and audiovisual translation. In M. Carroll, H. Gerzymisch-Arbogas \& S. Nauert (Eds.), Audiovisual Translation Scenarios: Proceedings of the Marie Curie Euroconferences MuTra: Audiovisual Translation Scenarios, Copenhagen 1-5 May 2006. Retrieved from https://www.euroconferences.info/proceedings/2006_Proceedings/2006_Gambier_Yves.p df

Gibson, J. J. (1979). The ecological approach to visual perception. Boston, MA; London, United Kingdom: Houghton Mifflin.

Greco, G. M. (2016a, February). Accessibility, human rights, and the ghetto effect. Paper presented at the Conference Wounded Places. On the Integrity of the Body, Beirut, Lebanon.

Greco, G. M. (2016b). On Accessibility as a human right, with an application to media accessibility. In A. Matamala \& P. Orero (Eds.), Researching Audio Description. New Approaches (pp. 1133). London, United Kingdom: Palgrave Macmillan.

Greco, G. M. (2017). L'accessibilità culturale come strumento per i diritti umani di tutti [Cultural accessibility as an instrument for the human rights of all]. In G. Cetorelli \& M. R. Guido (Eds.), II patrimonio culturale per tutti [Cultural heritage for all]. (pp. 94-102). Rome, Italy: Direzione Generale Musei, Ministero dei Beni e delle Attività Culturali e del Turismo.

Greco, G. M., Paronitti, G., Turilli, M., \& Floridi, L. (2005). How to do philosophy informationally. In K.-D. Althoff, A. Dengel, R. Bergmann, M. Nick, \& T. Roth-Berghofer (Eds.), Professional knowledge management: Third biennial conference, WM 2005, Kaiserslautern, Germany, April 10-13, 2005, Revised selected papers (pp. 623-634). Berlin, Germany: Springer.

Greco, G. M., \& Pedone, L. (2015). Accessibilità e sicurezza dei luoghi di spettacolo. Note su criteri impositivi, criteri prescrittivi e buone prassi [Accessibility, health and safety of live events venues]. Lecce, Italy: AGM.

Greco, G. M., Pedone, L., Monsellato, E., Rizzo, B., \& Spinelli, E. (2012). Guida per eventi accessibili ed ecosostenibili [Guide for accessible and ecosustainable events]. Lecce, Italy: Social SoundPuglia Sounds, Regione Puglia.

Holmes, J. S. (1988). The name and nature of translation studies. In J. S. Holmes (Ed.), Translated! Papers on literary translation and translation studies (pp. 66-80). Amsterdam, Netherlands: Rodopi.

Internet Society. (2017). Internet Society global Internet report: Paths to our digital future. Retrieved from https://www.internetsociety.org/

Jammer, M. (1999). Concepts of force. A study in the foundations of dynamics. Mineola, NY: Dover. Janelle, D. G. \& Hodge, D. C. (Eds.). (2000). Information, place and cyberspace: Issues in accessibility. New York, NY: Springer. 
Jankowska, A. (2017, November). When humanities meet IT. Mobile technologies for accessibility. Paper presented at the TransAccess: Translation and accessibility, Krakow, Poland.

Jankowska, A. (forthcoming). Audiovisual media accessibility. In E. Angelone, M. Ehrensberger-Dow \& G. Massey (Eds.), The Bloomsbury companion to language industry studies. London, United Kingdom: Bloomsbury Academic Publishing.

Kaptelinin, V., \& Nardi, B. A. (2006). Acting with technology. Activity theory and interaction design. Cambridge, MA; London, United Kingdom: MIT Press.

Klein, J. T. (1990). Interdisciplinarity. History, theory, and practice. Detroit, MI: Wayne State University Press.

Klein, J. T. (2009). The rhetoric of interdisciplinarity. Boundary work in the construction of new knowledge. In A. A. Lunsford, K. H. Wilson \& R. A. Eberly (Eds.), The SAGE handbook of rhetorical studies (pp. 265-283). Thousand Oaks, CA: SAGE.

Kraus, C. (2017). Introduction: Hand on, minds on. Motivation of the designbuild educator. In C. Kraus (Ed.), Designbuild education (pp. 1-16). London, United Kingdom: Routledge.

Levine, J., Grengs, J., \& Merlin, L. (forthcoming). The accessibility shift: Transforming transportation and land-use planning. Ithaca, NY: Cornell University Press.

Litman, T. (2017). Evaluating accessibility for transportation planning: Measuring people's ability to reach desired goods and activities. Victoria, Canada: Victoria Transport Policy Institute.

Mangiron, C. (2011). Accesibilidad a los videojuegos: estado actual y perspectivas futuras [Accessibility of video games: current state and futue perspectives]. TRANS. Revista de Traductología, 15, 53-67.

Mangiron, C. (2016). Reception of game subtitles: an empirical study. The Translator, 22(1), 72-93. Martín, A., Cechich, A., \& Rossi, G. (2011, March). Accessibility at early stages: Insights from the designer perspective. Paper presented at the International Cross-Disciplinary Conference on Web Accessibility, Hyderabad, India.

Morris, L. (2012). Rights, recognition and judgment: Reflections on the case of welfare and asylum. The British Journal of Politics and International Relations, 14(1), 39-56.

National Endowment for the Arts. (1992). The arts and 504: a 504 handbook for accessible arts programming (2 ed.). Washington, DC: National Endowment for the Arts.

NEM-ACCESS. (2016). Opening doors to universal access to the media. Retrieved from https://neminitiative.org/wp-content/uploads/2016/03/NEM-ACCESS-Policy-suggestions.pdf

Neurath, M. (1946). Isotype in films. Retrieved from http://isotyperevisited.org/1946/06/isotypein-films.html

Neurath, M. (1974). ISOTYPE. Instructional Science, 33(2), 127-150.

Neurath, M., \& Kinross, R. (2009). The transformer. Principles of making Isotype charts. London, United Kingdom: Hyphen.

Neurath, O. (1973a). Excerpt from the 'Memorandum of the visit by dr Otto Neurath to the borough of Bilston, July 24, 1945'. In M. Neurath \& R. S. Cohen (Eds.), Empiricism and sociology (pp. 75-78). Dordrecht, Netherlands; Boston, MA: Reidel.

Neurath, O. (1973b). Utopia as a social engineer's construction. In M. Neurath \& R. S. Cohen (Eds.), Empiricism and sociology (pp. 150-155). Dordrecht, Netherlands; Boston, MA: Reidel. 
Neurath, O. (1973c). Visual education and the Social and Economic Museum in Vienna. In M. Neurath \& R. S. Cohen (Eds.), Empiricism and sociology (pp. 215-218). Dordrecht, Netherlands; Boston, MA: Reidel.

Neurath, O. (1973d). Visual education: Humanisation versus popularisation. In M. Neurath \& R. S. Cohen (Eds.), Empiricism and sociology (pp. 227-248). Dordrecht, Netherlands; Boston, MA: Reidel.

Neves, J. (2016). Enriched descriptive guides: A case for collaborative meaning-making in museums Cultus, 2(9), 137-153

Norman, D. A. (2013). The design of everyday things. New York, NY: Basic Books.

O'Hagan, M., \& Mangiron, C. (2013). Game localization: translating for the global digital entertainment industry. Amsterdam, Netherlands;Philadelphia, PA: John Benjamins.

Orero, P. (2004). Audiovisual translation: A new dynamic umbrella. In P. Orero (Ed.), Topics in audiovisual translation (pp. VII-XIII). Amsterdam, Netherlands: Benjamins.

Orero, P. (2012). Film reading for writing audio descriptions: A word is worth a thousand images? In E. Perego (Ed.), Emerging topics in translation: Audio description (pp. 13-28). Trieste, Italy: EUT Edizioni Università di Trieste.

Orero, P., \& Matamala, A. (2007). Accessible opera: Overcoming linguistic and sensorial barriers. Perspectives: Studies in Translatology, 15, 262-277.

Perego, E., Del Missier, F., \& Stragà, M. (2018). Dubbing vs. subtitling: Complexity matters. Target, 30(1), 137-157.

Pérez-González, L. (2008). Audiovisual translation. In M. Baker \& G. Saldanha (Eds.), Routledge encyclopedia of translation studies (2nd ed., pp. 13-20). London, United Kingdom; New York, NY: Routledge.

Pérez-Ramos, A. (1988). Francis Bacon's idea of science and the maker's knowledge tradition. Oxford, United Kingdom: Clarendon Press.

Pheasant, S. (1996). Bodyspace: Anthropometry, ergonomics and the design of work (2nd ed.). London, United Kingdom: Taylor \& Francis.

Pietig, J. (1984). Is education a discipline? The Educational Forum, 48(3), 365-372.

Pöchhacker, F. (2018). Media interpreting. From user expectations to audience comprehension. In E. Di Giovanni \& Y. Gambier (Eds.), Reception studies and audiovisual translation (pp. 253227). Amsterdam, Netherlands: John Benjamins.

Pogge, T. (2011). Are we violating the human rights of the world's poor. Yale Human Rights \& Development Law Journal, 14(2), 1-33.

Price, D. J. d. S. (1963). Little science, big science. New York, NY: Columbia University Press.

Prodan, A. C. (2017). The sustainability of digital documentary heritage. In M.-T. Albert, F. Bandarin \& A. P. Roders (Eds.), Going beyond: Perceptions of sustainability in heritage studies. No. 2 (pp. 59-69). New York, NY: Springer.

Pullin, G. (2009). Design meets disability. Cambridge, MA: The MIT Press.

Rifkin, J. (2001). The age of access. How the shift from ownership to access is transforming modern life. London: Penguin. 
Romero-Fresco, P. (2013). Accessible filmmaking: Joining the dots between audiovisual translation, accessibility and filmmaking. The Journal of Specialised Translation(20), 201-223.

Romero-Fresco, P. (2017a). Accessible filmmaking in documentaries. Intralinea.

Romero-Fresco, P. (2017b, September). Widening the scope of media accessibility. Paper presented at the Intermedia. International Conference on Audiovisual Translation, Poznań, Poland.

Romero-Fresco, P. (2018). In support of a wide notion of media accessibility: Access to content and access to creation. Journal of Audiovisual Translation, 1(1), 187-204.

Romero-Fresco, P. (forthcoming). Accessible filmmaking: Integrating translation and accessibility into the filmmaking process. London, United Kingdom: Routledge.

Romero-Fresco, P. (Ed.) (2015). The reception of subtitles for the deaf and hard of hearing in Europe: UK, Spain, Italy, Poland, Denmark, France and Germany. Bern, Switzerland: Peter Lang.

Roulstone, A. (2016). Disability and technology: An interdisciplinary and international approach. London, United Kingdom: Palgrave Macmillan.

Salmen, J. P. S. (2000). The realities of facility accessibility. In E. B. Slavitt \& D. J. Pugh (Eds.), Accessibility under the Americans with Disabilities Act and other laws. A guide to enforcement and compliance (pp. 220-237). Chicago, IL: American Bar Association.

Salter, L., \& Hearn, A. M. V. (1996). Outside the lines. Issues in interdisciplinary research. Montreal, Canada: McGill-Queen's University Press.

Sanchez, T. W., \& Brenman, M. (2007). The right to transportation: Moving to equity. Chicago, IL: Planners Press.

Scanlon, J., Cassar, A., \& Nemes, N. (2004). Water as a human right? Gland, Switzerland; Cambridge, United Kingdom: International Union for Conservation of Nature and United Nations Development Programme.

Sen, A. (1985). Commodities and capabilities. Amsterdam, Netherlands; Oxford, United Kingdom: North-Holland.

Sense. (2006). Memorandum. In House of Commons. Culture, Media and Sport Committee (Ed.), Analogue switch-off. Second report of 2005-06. Volume II. Oral and written evidence (pp. 297-298). London, United Kingdom: The Stationery Office Limited.

Shadid, W., Prins, W., \& Mas, P. J. M. (1982). Access and oarticipation: A theoretical approach. In B. Galjart \& D. Buijs (Eds.), Participation of the poor in development (pp. 21-49). Leiden, Netherlands: Institute of Cultural and Social Studies, University of Leiden.

Shirley, B., \& Kendrick, P. (2006). The clean audio project: Digital TV as assistive technology. Technology and Disability, 18(1), 31-41.

Singh, N. (2016). Introduction. In N. Singh (Ed.), The human right to water: From concept to reality (pp. 1-16). Zurich, Switzerland: Springer.

Slater, J., Lindstrom, J.-I., \& Astbrink, G. (2010). Broadband solutions for consumers with disabilities. Ultimo NSW, Australia: Australian Communications Consumer Action Network.

Stephanidis, C. (2009a). Universal access and design for all in the evolving information society. In C. Stephanidis (Ed.), The universal access handbook (pp. 1.1-1.11). Boca Raton, FL: CRC Press. Stephanidis, C. (Ed.) (2009b). The universal access handbook. Boca Raton, FL: CRC Press. 
Stephanidis, C., \& Emiliani, P. L. (1999). Connecting to the information society: a European perspective. Technology and Disability, 10, 21-44.

Stephanidis, C., \& Salvendy, G. (1998). Toward an information society for all: An international research and development agenda. International Journal of Human-Computer Interaction, 10(2), 107-134.

Szarkowska, A., \& Jankowska, A. (2015). Audio describing foreign films. The Journal of Specialised Translation, 23, 243-269.

Szarkowska, A., Krejtz, I., Krejtz, K., \& Duchowski, A. (2013). Harnessing the potential of eyetracking for media accessibility. In S. Grucza, M. Płużyczka \& J. Zając (Eds.), Translation studies and eye-tracking analysis (pp. 153-183). Frankfurt am Main, Germany: Peter Lang.

Szarkowska, A., Krejtz, I., Pilipczuk, O., Dutka, Ł., \& Kruger, J.-L. (2016). The effects of text editing and subtitle presentation rate on the comprehension and reading patterns of interlingual and intralingual subtitles among deaf, hard of hearing and hearing viewers. Across Languages and Cultures, 17(2), 183-204.

Taylor, N., Caiafa, M., \& Brown, I. (2002). Involving the Public. In N. Taylor (Ed.), Accessibility and the bus system: From concepts to practice (pp. 257-288). Reston, VA: Thomas Telford.

Thompson, I. H. (2014). Landscape architecture. A very short introduction (First edition. ed.). Oxford, United Kingdom: Oxford University Press.

Thompson, T. (2003). The interdependent roles of all players in making technology accessible. Journal of Special Education Technology, 18(4), 21-27.

UN Committee on Economic, Social and Cultural Rights. (1999). General Comment 12: The right to adequate food (Art. 11). (E/C.12/1999/5). Geneva, Switzerland.

UNESCO Institute for Statistics. (2005). Introduction. In A. Abdul-Rahman (Ed.), Measuring linguistic diversity on the Internet (pp. 5-11). Paris, France: UNESCO.

Utray, F., de Castro, M., Moreno, L., \& Ruiz-Mezcua, B. (2012). Monitoring accessibility services in digital television. International Journal of Digital Multimedia Broadcasting, 2012, 9.

Vanderheiden, G. C. (1990). Thirty-something million: Should they be exceptions? Human Factors, 32(4), 383-396.

Vanderheiden, G. C. (1998). Universal design and assistive technology in communication and information technologies: Alternatives or complements? Assistive Technology: The Official Journal of RESNA, 10(1), 29-36.

Vardouli, T. (2015). Who designs? Technological mediation in design participation. In D. Bihanic (Ed.), Empowering users through design (pp. 13-45). Cham, Switzerland: Springer.

Varney, E. (2013). Disability and information technology: A comparative study in media regulation. Cambridge, United Kingdom: Cambridge University Press.

World Health Organization, \& World Bank. (2011). World report on disability. Geneva, Switzerland: World Health Organization

\footnotetext{
' Italics added, texts between parentheses are in the original paper.

"Italics added. The original text from the General Comment reads: "The right to adequate food, like any other human right, imposes three types or levels of obligations on States parties: the obligations to respect, to protect and to fulfil. In turn, the obligation to fulfil incorporates both an obligation to facilitate
} 
and an obligation to provide. The obligation to respect existing access to adequate food requires States parties not to take any measures that result in preventing such access. The obligation to protect requires measures by the State to ensure that enterprises or individuals do not deprive individuals of their access to adequate food. The obligation to fulfil (facilitate) means the State must pro-actively engage in activities intended to strengthen people's access to and utilization of resources and means to ensure their livelihood, including food security. Finally, whenever an individual or group is unable, for reasons beyond their control, to enjoy the right to adequate food by the means at their disposal, States have the obligation to fulfil (provide) that right directly" (UN Committee on Economic, Social and Cultural Rights, 1999, p. 5).

"II Although it has not been possible to trace the date of publication of FIA's advocacy paper, it may have been very likely published during the current presidency of Jean Todt, given the fact that he has made "sustainable mobility for all" a trademark of his mandate.

IV Note that the earliest accounts of MA did not include sign language interpreting, but only AD and SDH.

"The expression "products, services and environments" refers to the definition of accessibility provided in the World Report on Disability (see World Health Organization \& World Bank, 2011, p. 301). Hereafter, for brevity, I will collectively refer to them as "artefacts".

VI The expression "design of accessibility solutions and artefacts" should be intended in the most general sense, comprising from policies and legislation to computer software.

VII The expression "design of accessibility solutions and artefacts" should be intended in the most general sense, comprising a very broad range of concepts, from policies and legislation to computer software.

VIII Italics added.

${ }^{1 x}$ Some also include audio subtitles.

${ }^{x}$ See Fryer (2013) for an application of Gibson's theory to AD.

${ }^{X I}$ This is the English translation used by Neurath himself of "Gesellschafts- und Wirtschaftsmuseum in Wien".

XII It was a common practice of Marie Neurath, née Reidemeister, to sign her publications using her husband's surname.

XIII As already said, Neurath had already experimented with animated films in the 1920s. Sadly, no copies of them nor a detailed description of how they were made have survived, even though one could suppose they were created using the accessible methodology. Reports of a public screening of these films in New York in 1933 where published in The New York Times and the New York Herald Tribune (see Burke, 2013).

${ }^{X I V}$ In the original text the entire quote is in italics. Here, only one phrase is left in italics for emphasis. 